\title{
Validação de um Sistema Robotizado Recém Desenvolvido para a Soldagem pelo Processo Friction Stir Welding por meio da União e Caracterização de Juntas da Liga de Alumínio 5052 H34
}

\author{
Bruno Silva Cota $^{1}$, Alexandre Queiroz Bracarense ${ }^{1}$ \\ 1 Universidade Federal de Minas Gerais - UFMG, Programa de Pós-Graduação em Engenharia Mecânica, Belo Horizonte, MG, Brasil.
}

Recebido: 14 Nov., 2017

Aceito: 24 Nov., 2017

E-mail: brunocota@ufmg.br (BSC)
Este é um artigo publicado em acesso aberto (Open Access) sob a licença Creative Commons Attribution Non-Commercial, que permite uso, distribuição e reprodução em qualquer meio, sem restriçōes desde que sem fins comerciais e que 0 trabalho original seja corretamente citado.
Resumo: Este projeto trata da validação de um sistema recém desenvolvido para a soldagem pelo processo friction stir welding, que foi adaptado a um robô antropomórfico com capacidade de $500 \mathrm{~kg}$ e seis graus de liberdade. Para garantir que o sistema projetado é capaz de soldar materiais pelo processo FSW, ou seja, garantir que possui rigidez, resistência e torque suficientes para realizar a operação de soldagem, faz-se necessário realizar a validação do mesmo. Para tanto, foi necessário soldar um material conhecido, com parâmetros já estabelecidos, e utilizar uma ferramenta apropriadamente dimensionada. Dessa forma, escolheu-se a liga 5052 H43 de 3 mm de espessura, usada na produção de navios, embarcações e estruturas automotivas. Para a soldagem das juntas finais foi usada uma ferramenta fabricada em AISI H13, com pino cônico liso e diâmetro do ombro de $18 \mathrm{~mm}$. A velocidade rotacional da ferramenta foi mantida constante em $378 \mathrm{rpm}$, e a velocidade de avanço em 7,5 mm/min, sendo a inclinação da ferramenta de $2^{\circ}$. Verificou-se após os ensaios que o sistema de soldagem projetado se mostrou eficaz em aplicações de soldagem FSW, apresentando torque e resistência mecânica suficientes para a união de materiais com baixo ponto de fusão. Por meio dos parâmetros utilizados, bem como da geometria da ferramenta, foi possivel obter juntas da liga de alumínio 5052 H34 soldadas com: bom aspecto superficial, baixos valores de rebarba, ausência de sulcos ou vazios ao longo da linha de soldagem e com penetração total.

Palavras-chave: Friction stir welding; Soldagem; Robotização; Fricção; Industrial.

\section{Validation of a Newly Developed Robotic System for Friction Stir Welding Process by Joining and Characterizing Joints Of Aluminum Alloy 5052 H34}

\begin{abstract}
This project deals with the validation of a newly developed system for a welding by friction welding process, which was adapted to an anthropomorphic robot with a capacity of $500 \mathrm{~kg}$ and six degrees of freedom. To ensure that the designed system is capable of soldering materials for the FSW process, that is, make sure that it has sufficient stiffness, strength and torque to perform a welding operation, it is necessary to perform a calibration of the same. To do so, it was necessary to find a known material, with already established parameters, and to use an appropriately sized tool. In this way, the alloy $5052 \mathrm{H} 43$ of $3 \mathrm{~mm}$ thickness was used, used in the production of ships, boats and automotive structures. For a welding of the finished joints, it was manufactured in AISI H13, with smooth conical pin and shoulder diameter of $18 \mathrm{~mm}$. The rotational speed of the tool was kept constant at $378 \mathrm{rpm}$, and an advance speed of $7.5 \mathrm{~mm} / \mathrm{min}$, with a tool slope of $2^{\circ}$. It was verified after the tests that the designed welding system proved to be effective in FSW welding applications, presenting sufficient torque and mechanical strength for a union of materials with low melting point. Through the parameters used, as well as the geometry of the tool, it is possible to obtain 5052 H34 aluminum alloy seals welded with: good surface appearance, low burr values, no grooves or voids along the welding line and with total penetration.
\end{abstract}

Key-words: Friction stir welding; Welding; Robotization; Friction; Industrial.

\section{Introdução}

O processo de soldagem por atrito com pino não consumível (SAPNC), mais conhecido como Friction Stir Welding (FSW), foi inventado por Wayne Thomas e um time de pesquisadores no início da década de 1990 em Cambridge, no Reino Unido [1]. O TWI (The Welding Institute), onde a técnica foi criada, é uma das organizações de pesquisa e tecnologia independentes mais importantes do mundo, com experiência em união de materiais e processos de engenharia aplicados na indústria. De acordo com Fonseca [2], o processo FSW tem sido motivo de intensa pesquisa e tem ganhado relevância no setor produtivo devido às suas diversas vantagens técnicas e econômicas. 
Validação de um Sistema Robotizado Recém Desenvolvido para a Soldagem pelo Processo Friction Stir Welding por meio da União e Caracterização de Juntas da Liga de Alumínio 5052 H34

Inicialmente utilizado por indústrias automotivas e aeroespaciais, o processo passou de uma simples técnica de soldagem de chapas finas de ligas de alumínio para um processo adaptável de grande utilização na união de ligas de metais leves, titânio, aço e outros metais duros de pequenas espessuras [3]. O notável crescimento deste processo de soldagem pode ser explicado, também, pela possibilidade de união com sucesso de materiais até então considerados não soldáveis ou de difícil soldabilidade.

De acordo com Capelari e Mazzaferro [4], apesar da técnica de soldagem pelo processo FSW ter merecido destaque, sendo objeto de estudo em diversos centros de pesquisa tecnológica e Universidades do exterior, pouco se tem observado quanto a trabalhos realizados inteiramente no Brasil. De acordo com os autores, um dos motivos para isto certamente reside na necessidade de um alto investimento para a obtenção dos equipamentos específicos à soldagem FSW. Além disso, de acordo com Backer [5], apesar do processo FSW estar sendo objeto de estudo em vários centros de pesquisa no mundo, poucos estudam sua aplicação em robôs industriais, em que se destacam os institutos e as empresas: HGZ (Helmholtz-Zentrum Geesthacht), IWB e KUKA (em conjunto com o Grupo Airbus), na Alemanha; a ESAB, na Suécia; Institut Maupertuis e Institut de Soudure, na França; Cewac, na Bélgica; Friction Stir Link, nos Estados Unidos. Neste contexto, o maior avanço tecnológico que se tem conhecimento é o desenvolvimento de uma tecnologia robotizada para a soldagem de alumínio e aço, aplicada na produção em série de um veículo pela Honda Motor Co [6,7].

Neste contexto, a primeira etapa deste projeto foi baseada no dimensionamento de um sistema robotizado para a soldagem pelo processo FSW. Sendo assim, foi realizado o dimensionamento dos eixos, mancais, porta-ferramentas, dentre outros dispositivos necessários ao correto funcionamento do sistema. Em seguida, foi necessário escolher o tipo de transmissão (corrente, correia, engrenagens) para fazer o acionamento do eixo principal. De modo geral, o sistema dimensionado deveria ter alto torque para suportar a soldagem de materiais com elevado ponto de fusão e peso reduzido, uma vez que seria adaptado a um robô industrial. A montagem experimental realizada é apresentada na Figura 1, em que é possível verificar o robô antropomórfico COMAU NJ500 de 6 graus de liberdade (A) que foi usado para a adaptação do sistema de soldagem projetado (B). A base de soldagem é a mesa de uma furadeira de coluna adaptada como estrutura para a fixação das chapas a serem unidas pelo processo FSW (Figura 1C). Para fazer o controle da rotação do sistema de soldagem foi utilizado um inversor de frequência com capacidade de acionamento de motores de até $50 \mathrm{cv}$.

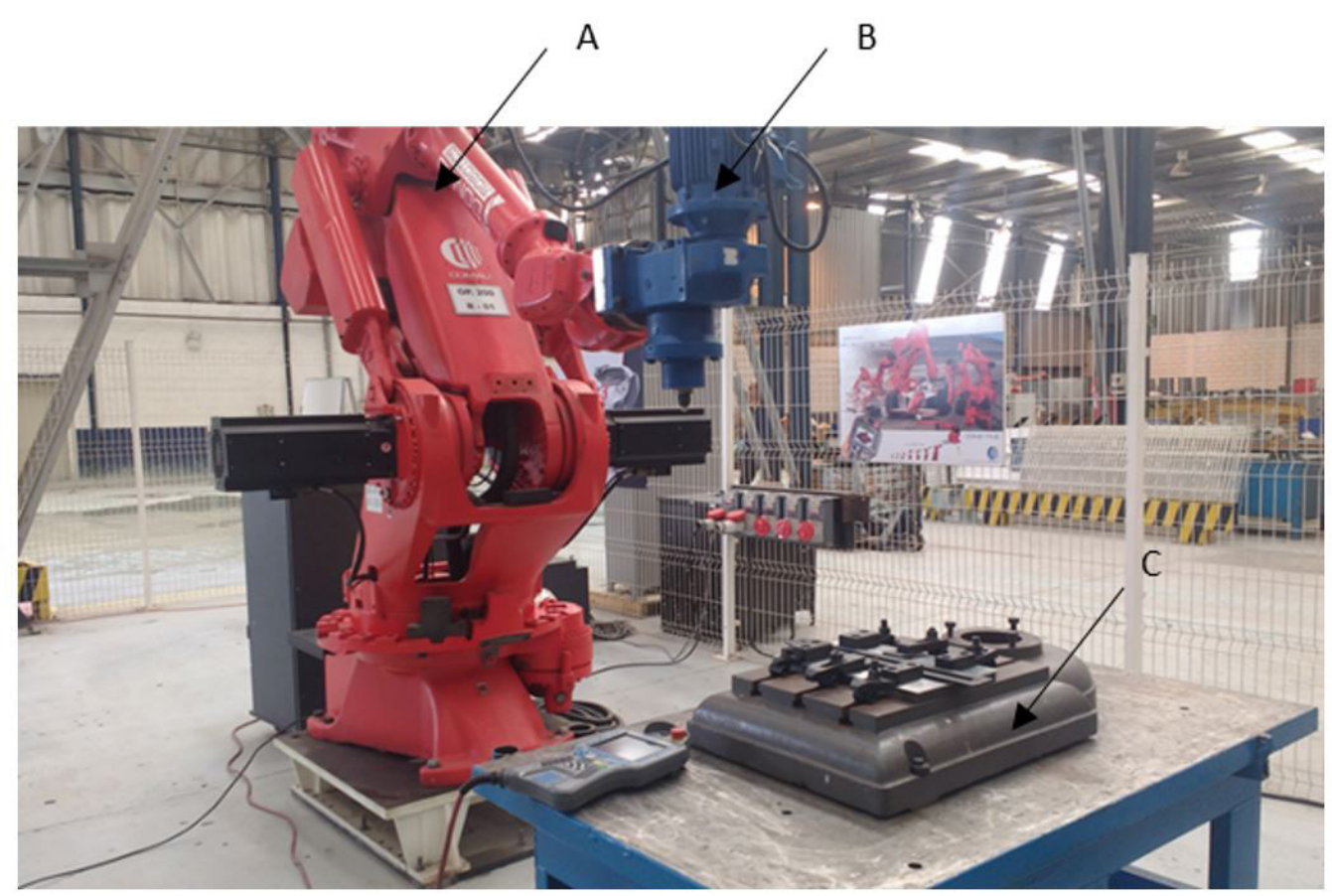

Figura 1. Montagem experimental: (A) robô antropomórfico COMAU NJ500; (B) dispositivo de soldagem; (C) base de soldagem. 
O sistema de soldagem foi projetado para permitir a soldagem de materiais com elevado ponto de fusão, ou mesmo para a soldagem de materiais dissimilares. Para certificar que o sistema robotizado dimensionado era capaz de soldar materiais pelo processo FSW, ou seja, garantir que possui rigidez, resistência e torque suficientes para realizar a operação de soldagem, faz-se necessário realizar a validação do mesmo. Para tanto, foi necessário soldar um material conhecido, com parâmetros já estabelecidos, e utilizar uma ferramenta apropriadamente dimensionada.

\section{Materiais e Métodos}

\subsection{Material}

Para a realização da validação do sistema foi utilizada a liga Al 5052 H34 de 3 mm de espessura, que possui como principal elemento o magnésio, sendo considerada de excelente soldabilidade e com boa resistência à corrosão, principalmente em atmosfera salina. A série Al 5xxx possui aplicações em diferentes setores produtivos, passando por produtos que variam desde navios e embarcações, tanques de gasolina, placas de sinalização até estruturas automotivas [8].

A composição química e as propriedades mecânicas da liga Al 5052 H34 são apresentadas nas Tabelas 1 e 2 . Verifica-se que o principal elemento da liga é o magnésio, que é mais efetivo que o manganês (elemento utilizado em outras séries de ligas) em relação ao aumento da resistência, o que faz com que as ligas da série 5xxx tenham uma resistência mecânica razoável.

Tabela 1. Limites de composição química para a liga Al 5052 [9].

\begin{tabular}{ccccccccc}
\hline $\mathbf{A l}$ & $\mathbf{M g}$ & $\mathbf{S i}$ & $\mathbf{F e}$ & $\mathbf{Z n}$ & $\mathbf{C u}$ & $\mathbf{P b}$ & $\mathbf{M n}$ & $\mathbf{C r}$ \\
97,181 & 2,340 & 0,032 & 0,22 & 0,003 & 0,014 & 0,006 & 0,038 & 0,166 \\
\hline
\end{tabular}

Tabela 2. Propriedades mecânicas da liga Al 5052 H34 [9].

\begin{tabular}{|c|c|c|c|c|c|c|c|}
\hline \multirow{2}{*}{ 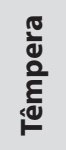 } & \multicolumn{2}{|c|}{$\begin{array}{l}\text { Espessura especificada } \\
{[\mathrm{mm}]}\end{array}$} & \multicolumn{2}{|c|}{$\begin{array}{l}\text { Limite de Resistência a } \\
\text { Tração [Mpa] }\end{array}$} & \multicolumn{2}{|c|}{$\begin{array}{l}\text { Limite de Escoamento } \\
\text { [Mpa] }\end{array}$} & \multirow{2}{*}{$\begin{array}{l}\text { Alongamento (\%) } \\
\text { Mín, em } 50 \text { mm }\end{array}$} \\
\hline & Inferior & Superior & Mínimo & Máximo & Mínimo & Máximo & \\
\hline H34 & 3,2 & 6,3 & 235 & 285 & 180 & $* *$ & 6 \\
\hline
\end{tabular}

**Valor não determinado na norma ASTM B209M.

\subsection{Parâmetros de soldagem}

Devido à grande variedade de parâmetros fornecidos pela literatura, foram realizadas juntas soldadas preliminares variando os parâmetros, visando à obtenção de valores para as velocidades de rotação, avanço e inclinação da ferramenta. A avaliação nesta etapa foi realizada considerando o aspecto da superfície do cordão de solda e o comportamento da ferramenta durante a soldagem.

Os parâmetros finais usados durante a soldagem da liga Al 5052 H34 com 3 mm de espessura são apresentados na Tabela 3, em que verifica-se que a velocidade rotacional da ferramenta foi mantida constante em $378 \mathrm{rpm}$, e a velocidade de avanço de $7,5 \mathrm{~mm} / \mathrm{min}$. A rotação foi medida experimentalmente por meio de um tacômetro digital modelo DT-2234C, com resolução de 0,1 rpm e precisão de $\pm 0,05 \%+1$ dígito.

Tabela 3. Parâmetros finais para a soldagem da liga Al 5052 H34.

\begin{tabular}{|c|c|c|c|c|c|}
\hline $\begin{array}{l}\text { Velocidade } \\
\text { de Avanço } \\
\text { [mm/min] }\end{array}$ & $\begin{array}{c}\text { Sentido } \\
\text { de Rotação }\end{array}$ & $\begin{array}{l}\text { Velocidade de } \\
\text { Rotação [rpm] }\end{array}$ & Penetração [mm] & $\begin{array}{c}\text { Ângulo de } \\
\left.\text { Inclinação [ }{ }^{\circ}\right]\end{array}$ & $\begin{array}{c}\text { Tempo } \\
\text { de Espera [s] }\end{array}$ \\
\hline 7,5 & Horário & 378 & 2,9 & 2 & 20 \\
\hline
\end{tabular}


Validação de um Sistema Robotizado Recém Desenvolvido para a Soldagem pelo Processo Friction Stir Welding por meio da União e Caracterização de Juntas da Liga de Alumínio 5052 H34

Para o teste definitivo a ferramenta sofreu uma inclinação de $2^{\circ}$, e o tempo de espera (dwell time) antes de iniciar o translado da ferramenta foi de $20 \mathrm{~s}$. Para a verificação do ângulo, foi utilizado o medidor de inclinação digital da marca INSIZE, modelo $2178-1$, com capacidade de medição $0-180^{\circ}$, resolução $0,1^{\circ}$ e exatidão de $\pm 0,1^{\circ}$, que foi fixado no cabeçote do sistema de soldagem por meio de sua base magnética. As soldas foram realizadas com sentido horário de rotação.

\subsection{Ferramenta}

As dimensões principais da ferramenta usada na soldagem da liga Al 5052 H34 com 3 mm de espessura são apresentadas na Figura 2, em que verifica-se que a mesma possui pino cônico com inclinação de $10^{\circ}$, o que contribui para distribuição e redução das forças envolvidas no processo durante a fase de penetração da ferramenta. Verifica-se ainda que as dimensões da ferramenta estão de acordo com as indicações de diversos autores, que recomendam que o diâmetro do pino seja próximo à espessura das chapas a serem soldadas. Além disso, o comprimento do pino deve ser um pouco inferior a espessura da chapa a ser soldada e o diâmetro do ombro da ferramenta deve corresponder a 3 vezes o diâmetro maior do pino [4,10-13].

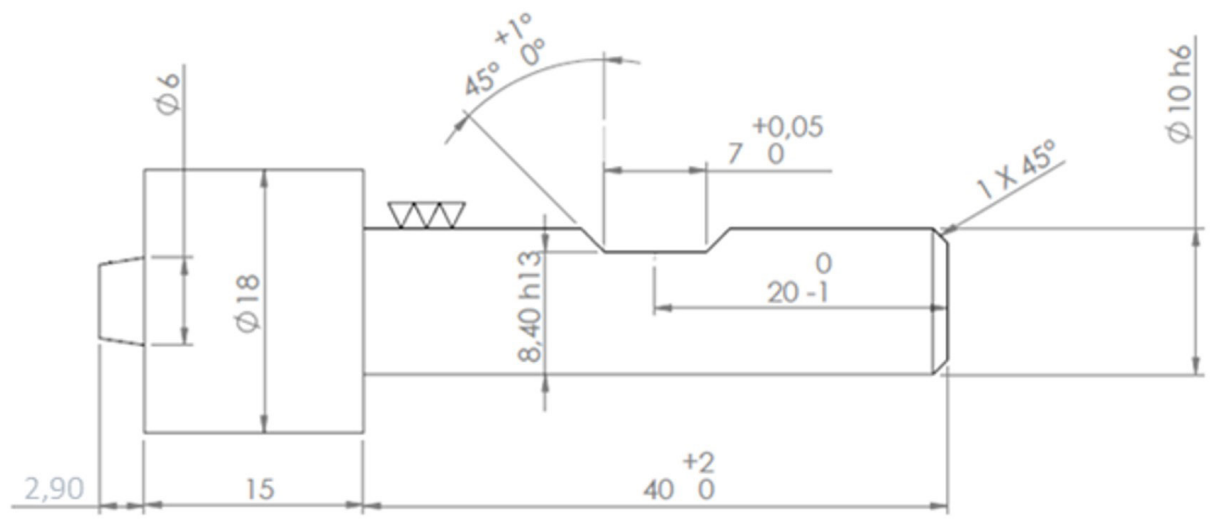

Figura 2. Dimensões principais da ferramenta usada no processo FSW para soldagem da liga Al 5052 H34.

Foi escolhido o material AISI H13 para a fabricação das ferramentas, por ser o mais comumente usado na soldagem de ligas de alumínio e devido à alta resistência mecânica e boa resistência ao desgaste em temperaturas elevadas $[6,14,15]$. Foram fabricadas duas ferramentas para esta etapa, e as mesmas não foram submetidas a tratamentos térmicos, possuindo dureza média de $25 \mathrm{HRC}$, verificada por meio de testes experimentais.

\subsection{Caracterização das juntas soldadas}

Após a realização das soldas nos corpos de prova, foram retiradas amostras para realização dos ensaios destrutivos e não destrutivos para a caracterização das juntas. Para cada solda realizada nos testes definitivos foram retiradas três amostras para ensaio de tração (TR1, TR2 e TR3) e duas amostras representativas (M1 e M2) para análise metalográfica e medição do perfil de dureza. Conforme recomendado pela norma ISO 25239-4:2011 "Friction stir welding - Aluminium - Specification and qualification of welding procedures" [16], os $50 \mathrm{~mm}$ iniciais e finais de cada solda foram descartados, o que satisfaz também a norma AWS B4.0-98, que recomenda $20 \mathrm{~mm}$.

\subsubsection{Ensaio de tração}

Para a medida da resistência à tração das chapas soldadas foi utilizada a máquina INSTRON, modelo 5982 do Departamento de Engenharia de Materiais do CEFET-MG. O teste foi executado a uma velocidade de $4,5 \mathrm{~mm} / \mathrm{min}$. Foram extraídas três amostras para o ensaio de tração, confeccionados conforme norma DIN EN ISO 4136:2013 "Destructive tests on welds in metallic materials - Transverse tensile test" [17], na direção transversal à solda para determinação do limite de resistência à ruptura, escoamento e o alongamento percentual do material após a soldagem (Figura 3). 


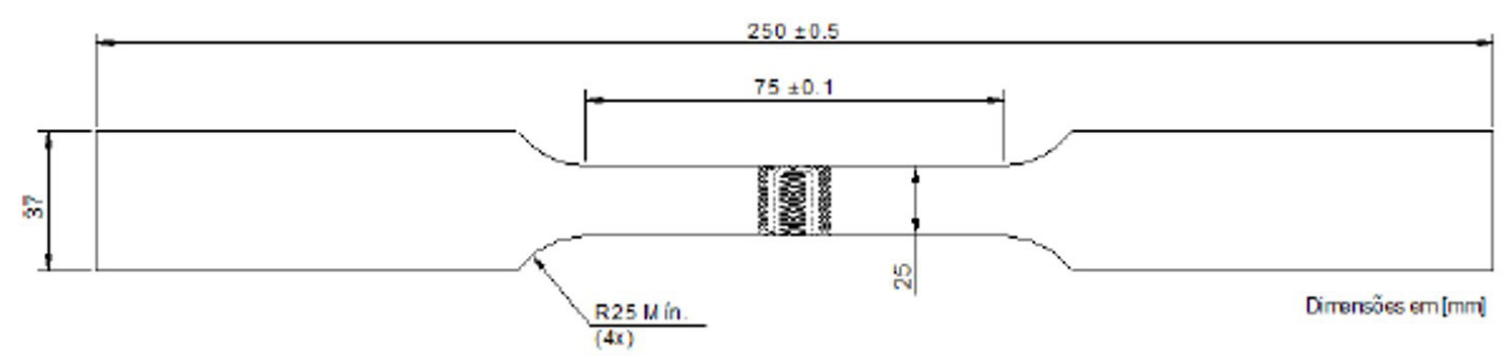

Figura 3. Dimensões dos corpos de prova soldados para o ensaio de tração.

Três amostras foram retiradas da chapa comercial utilizada para fabricação das peças base, extraídas perpendicularmente à direção de laminação, seguindo norma ABNT NBR 7549:2011 - "Alumínio e suas ligas - Produtos laminados, extrudados e fundidos - Ensaio de tração" [18], com o objetivo de possibilitar uma avaliação das perdas de resistência do material soldado em relação ao original (Figura 4).

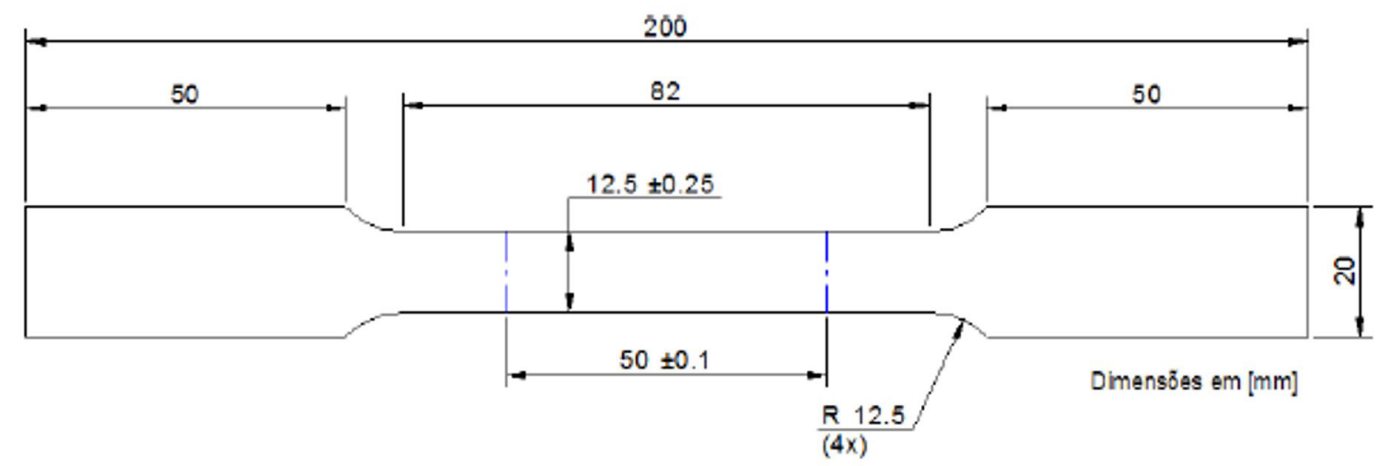

Figura 4. Dimensões dos corpos de prova para a realização do ensaio de tração no metal de base.

\subsubsection{Análise metalográfica}

Primeiramente, foi realizada uma análise visual da qualidade das juntas soldadas, em que foi verificada a possível presença de defeitos macroscópios superficiais e internos da junta. A largura do cordão de solda, por sua vez, foi medida utilizando um paquímetro da marca Mitutoyo, com resolução de 0,02 $\mathrm{mm}$. Após a preparação, as amostras foram analisadas nos microscópios Olympus SZ-CTV e Olympus BX60M, com fotômetro e câmera de captura de imagem. As imagens foram capturadas utilizando o software HLImage. Em seguida, foram realizados os ensaios de Microdureza no aparelho SHIMADZU HMV, para verificar as possíveis alterações na zona fundida, na ZTA e na ZTMA das amostras soldadas.

\subsubsection{Ensaio de dureza por microindentação}

Os ensaios de dureza por microindentação foram realizados nas mesmas amostras retiradas para os ensaios metalográficos, em que foi utilizada a Norma DIN EN 9015-2:2011 - "Destrutive test on welds in metallic materials - Hardness test-Part 2: Microhardness testing of welded joint" para determinação do perfil transversal de dureza da solda.

Os ensaios de microindentação foram realizados em um Microindentador Digital SHIMADZU HMV, com penetrador piramidal de diamante de $136^{\circ}$ de conicidade. As medidas foram realizadas com a movimentação do corpo de prova sobre a bancada do aparelho, com observação por uma lente de ampliação de 40 vezes. Foram realizadas 64 indentações com espaçamento de $0,5 \mathrm{~mm}$, igualmente distribuídas em um intervalo de $32 \mathrm{~mm}$, com uma carga de 4,903 N, aplicada por 10 segundos (Figura 5). 

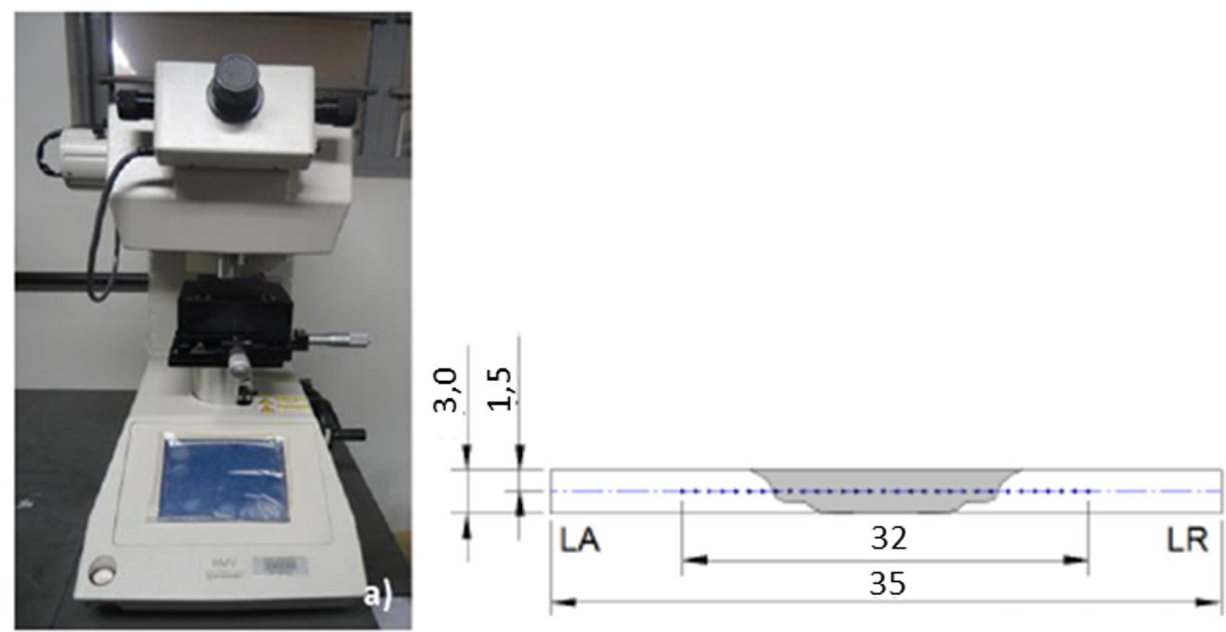

b)

Figura 5. Ensaio de microdureza: (a) Microindentador digital usado nos ensaios, (b) Representação esquemática da seção transversal das amostras utilizadas para análises de microdureza.

\subsection{Medidas de temperatura}

A fim de identificar possíveis não conformidades no sistema durante a soldagem, foi realizado o monitoramento da temperatura, nos pontos apresentados na Figura 6. Para tanto, foi utilizado um termômetro infravermelho com mira a laser do fabricante Instrutherm, modelo TI-870, com possibilidade de medição de $-50^{\circ} \mathrm{C}$ a $550{ }^{\circ} \mathrm{C}$, precisão de $\pm 2 \%$ da leitura e resolução de $0,1^{\circ} \mathrm{C}$. As medidas foram tomadas durante todo o processo de soldagem, em intervalos de aproximadamente 1 minuto.

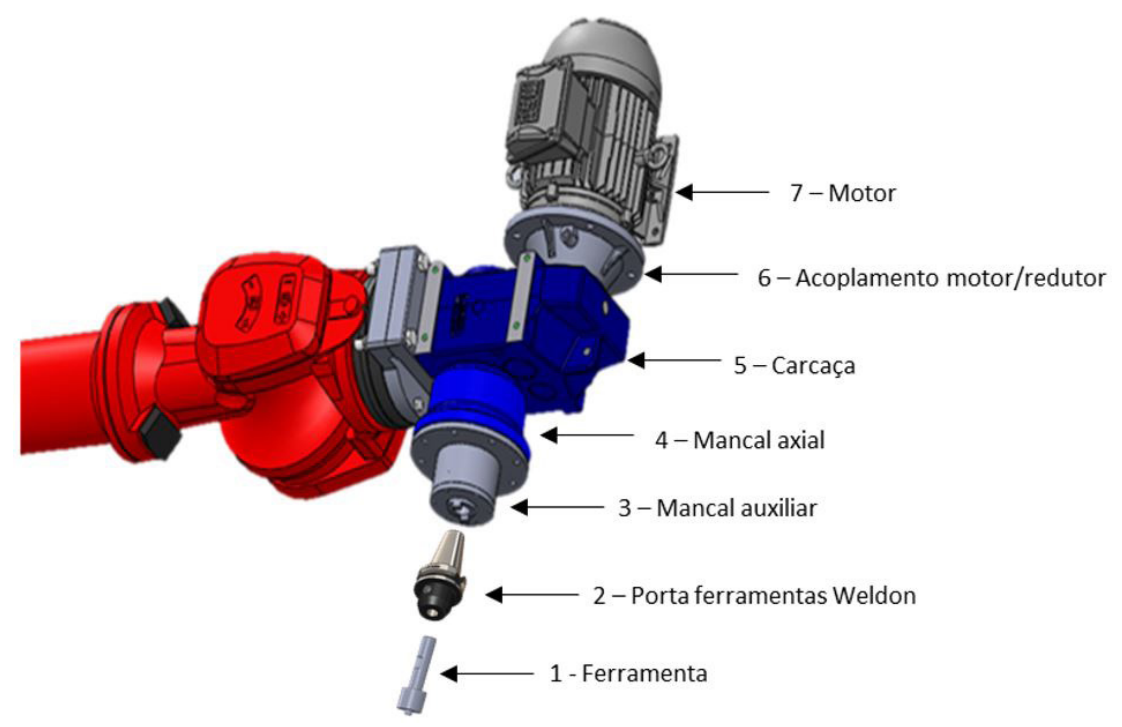

Figura 6. Pontos de verificação da temperatura no sistema de soldagem.

Além disso, foi verificada a distribuição da temperatura nas chapas de alumínio, em que quatro termopares foram dispostos no centro da amostra, perpendiculares à linha de soldagem, conforme realizado por Zhu \& Chao [19]. Foram utilizados termopares minerais blindados do tipo k, com diâmetro de $1 \mathrm{~mm}$ e comprimento de $50 \mathrm{~mm}$, revestidos com fibra e trança. Os termopares (T1, T2, T3 e T4) foram inseridos no lado de avanço e, em seguida, no lado de retrocesso das chapas por meio de furos realizados com uma broca de $1 \mathrm{~mm}$ em uma profundidade 
de $1,5 \mathrm{~mm}$, correspondendo à metade da espessura das amostras, conforme apresentado na Figura 6. Foi realizado um cordão de solda com comprimento de $140 \mathrm{~mm}$, sendo a temperatura medida na metade do processo, em um comprimento de $70 \mathrm{~mm}$. O primeiro termopar (T1) foi posicionado a $15 \mathrm{~mm}$ da linha de soldagem e os demais (T2, T3 e T4) a 25, 35 e $45 \mathrm{~mm}$, respectivamente. Um segundo teste foi realizado com os termopares (T1, T2, T3 e T4) posicionados a 15, 20, 30 e $40 \mathrm{~mm}$ da linha de soldagem, respectivamente (Figura 7).

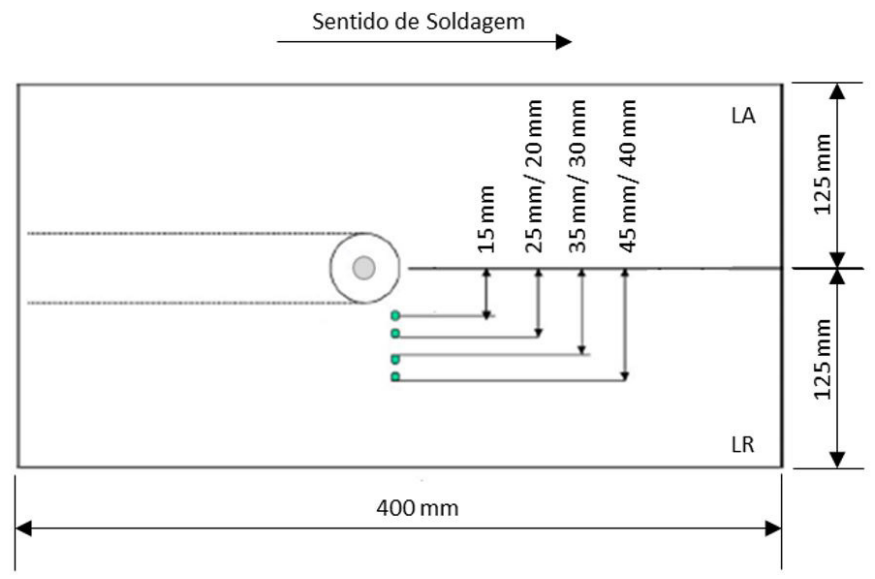

Figura 7. Montagem experimental para a aquisição da temperatura durante a soldagem.

Para leitura dos dados de temperatura, foi utilizado o sistema de aquisição portátil SAP $4 \mathrm{~V} T i$, que possui oito canais para a aquisição de temperatura, fabricado pelo IMC Soldagem ${ }^{\circledR}$, conforme apresentado na Figura 8.
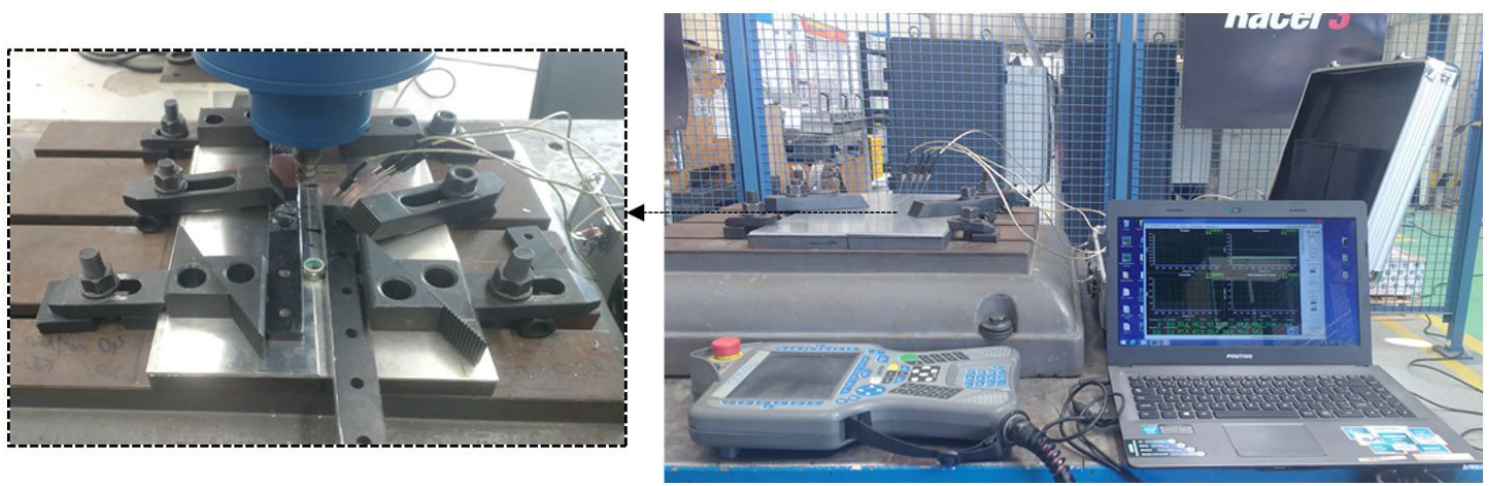

Figura 8. Sistema para a aquisição de dados de temperatura SAP 4V Ti e posicionamento dos termopares.

\section{Resultados e Discussão}

Inicialmente foram realizados pré-testes a fim de fazer os ajustes necessários para se obter juntas soldadas com o mínimo ou, até mesmo, com a ausência de defeitos superficiais. Dessa forma, foram variados os parâmetros: velocidade de rotação, velocidade de avanço e o ângulo de inclinação da ferramenta, a fim de produzir soldas com:

- Baixo valor de rebarbas;

- Ausência de sulcos ou vazios ao longo da linha de soldagem;

- Penetração total visual.

Além disso, foi observado o comportamento do sistema de soldagem durante a execução dos testes, em que procurou-se utilizar parâmetros em que fosse possível reduzir as vibrações e ruídos no sistema de soldagem e no robô, bem como manter a temperatura dentro dos níveis aceitáveis para os componentes. Nesta etapa do projeto 
foi possível estabelecer o domínio do processo de soldagem, visto que se tratou de um sistema novo e adaptado a um robô, o que gerou uma série de incertezas. Além disso, os pré-testes tiveram como objetivo identificar a influência das variáveis no contexto do processo FSW.

Verificou-se durantes os testes iniciais que, em função da elevada força envolvida no processo, o robô saia da trajetória programada durante a soldagem, proporcionando o aquecimento irregular da junta e acarretando em problemas de solda fria, como pode ser observado na Figura 9. Problemas de vibração excessiva em robôs adaptados ao processo FSW já haviam sido relatadas por Smith [20], que afirmou que a introdução de um hardware para controle das forças envolvidas no processo FSW é inviável em função dos custos e problemas de manutenção.

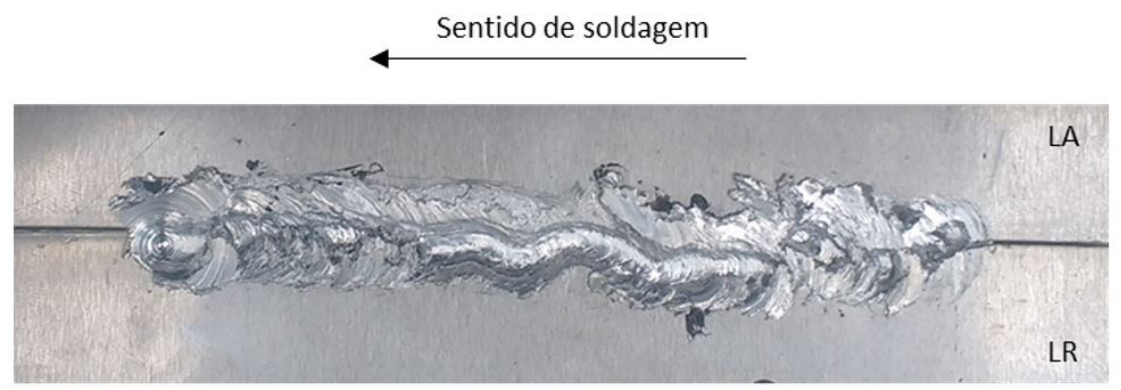

Figura 9. Solda com elevados defeitos superficiais em função da utilização de parâmetros incorretos e pela alteração da trajetória de soldagem pelo robô.

Para este projeto, juntas soldadas com bom aspecto superficial só foram obtidas após a alteração do sistema de fixação das chapas, em que foi modificado o posicionamento dos grampos de fixação, de modo que as travas fossem montadas contra as chapas de alumínio. Além disso, foi criada uma guia que auxiliava durante a realização da trajetória, forçando o braço do robô para a junta no caso de um possível desvio (Figura 10). Em testes posteriores identificou-se que as causas dos movimentos irregulares dos braços do robô na direção " $y$ " se dava quando havia baixa penetração da ferramenta na chapa.
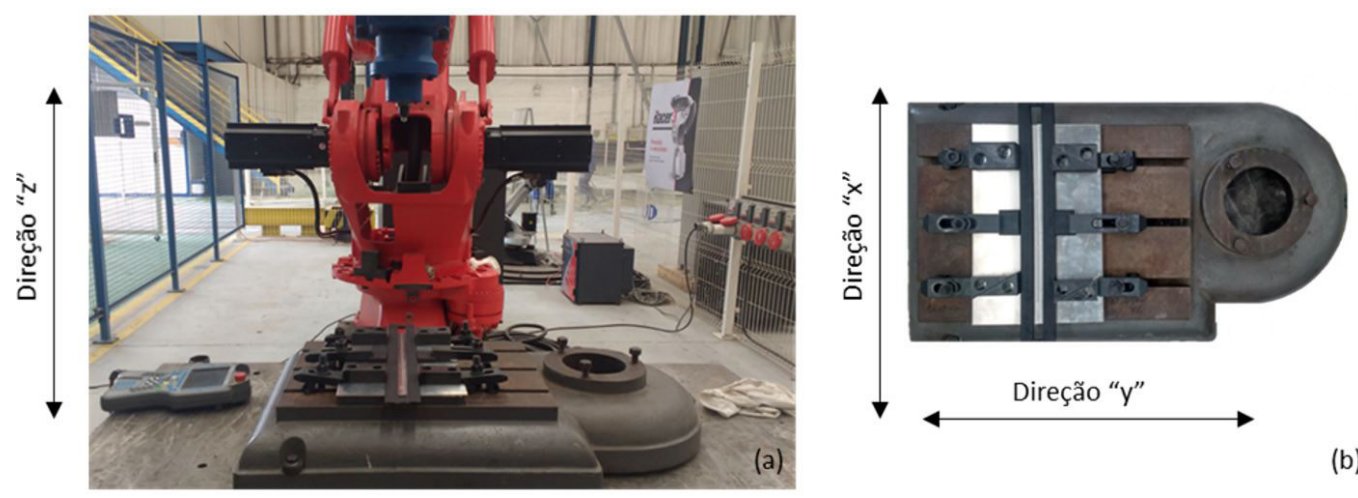

(b)

Figura 10. (a) sistema de fixação das chapas e guia de soldagem; (b) vista superior da mesa.

O resumo dos parâmetros usados nos pré-testes é apresentado na Tabela 4, sendo que esta etapa não seguiu a um critério temporal, e foi baseada nos resultados desprendidos destas experiências e a forma como foram abordadas para a sua análise. Alguns testes foram realizados com pré-furos nas chapas para a redução das forças durante a imersão da ferramenta, em que foi utilizada uma broca um diâmetro ligeiramente inferior ao diâmetro do pino [21]. Dessa forma, foi possível reduzir as vibrações do robô no momento da imersão, entretanto, o calor produzido pela entrada da ferramenta foi insuficiente, mesmo com o aumento da rotação, o que inviabilizou a utilização desta técnica por gerar soldas frias. 
Tabela 4. Parâmetros usados nos testes preliminares para a soldagem da liga de alumínio 5052 H34.

\begin{tabular}{cccccc}
\hline Teste & Sentido de rotação & $\begin{array}{c}\text { Velocidade de } \\
\text { Avanço }[\mathbf{m m} / \mathbf{m i n}]\end{array}$ & $\begin{array}{c}\text { Velocidade de } \\
\text { Rotação [rpm] }\end{array}$ & $\begin{array}{c}\text { Ângulo de } \\
\text { Inclinação [ }{ }^{\circ} \text { ] }\end{array}$ & Pré-furo \\
A2 & Horário & 12,5 & 315 & 1 & $\mathrm{~N}$ \\
A2 & Horário & 12,5 & 342 & 1 & $\mathrm{~S}$ \\
A3 & Horário & 12,5 & 499 & 1 & $\mathrm{~S}$ \\
B1 & Horário & 10 & 315 & 1 & $\mathrm{~S}$ \\
B2 & Horário & 10 & 342 & 1 & $\mathrm{~N}$ \\
B3 & Horário & 10 & 499 & 1 & $\mathrm{~N}$ \\
C1 & Horário & 7,5 & 315 & 1 & $\mathrm{~N}$ \\
C2 & Horário & 7,5 & 378 & 1 & $\mathrm{~N}$ \\
D1 & Horário & 7,5 & 315 & 1 & $\mathrm{~S}$ \\
D2 & Horário & 7,5 & 378 & 1 & $\mathrm{~N}$ \\
D3 & Horário & 7,5 & 378 & 2 & $\mathrm{~N}$ \\
\hline
\end{tabular}

As vistas de topo das superfícies dos cordões de solda produzidos pelos parâmetros usados nos pré-testes são apresentadas na Figura 11. Foi possível obter soldas com bom aspecto superficial, ausência de rebarbas e penetração total ao utilizar os parâmetros que produziram a junta D3.
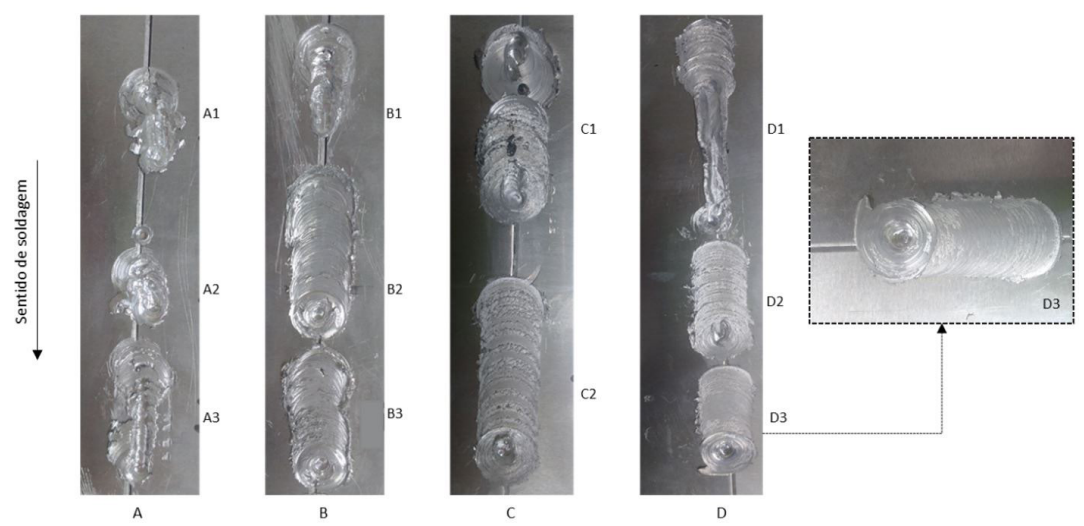

Figura 11. Soldas de topo realizadas nas chapas de alumínio 5052 H34 durante os pré-testes.

Uma vez definidos os parâmetros para a soldagem final foram realizadas duas juntas com iguais parâmetros de soldagem, sendo uma com a ferramenta usada nos pré-testes e outra com uma ferramenta nova. A Figura 12 apresenta as imagens em vista de topo das soldas realizadas nas chapas de alumínio 5052 H34 com a ferramenta usada (A) e com a ferramenta nova (B). Verificou-se por meio de um paquímetro que a largura do cordão de solda correspondeu em toda sua extensão ao diâmetro do ombro do pino, evidenciando que não houve vibração dos braços do robô durante o processo.

Verificou-se em ambas as amostras a presença de rebarbas (flash), depositadas no lado de retrocesso das chapas, assim como observado por outros autores [6,14,22]. A formação de rebarbas pode estar ligada ao comprimento pequeno do pino que permite maior penetração da ferramenta por não se aproximar da raiz da solda, e assim favorece a expulsão do material [23]. Entretanto, neste projeto a geometria da ferramenta não foi o fator responsável pela produção de rebarbas. Um fator que contribuiu para a maior geração de rebarbas foi a baixa velocidade de avanço, o que ocasionou aportes térmicos elevados e proporcionou um fluxo de material excessivo, facilitando a expulsão do material [6].

Para ambas as soldas, foi verificada a ausência de defeitos superficiais macroscópicos ao longo da junta soldada. Após a soldagem, entretanto, foi verificado o empenamento das amostras, fato pouco comentado na literatura e observado por Almeida [6] durante seus ensaios com a liga de alumínio 5182-O. 


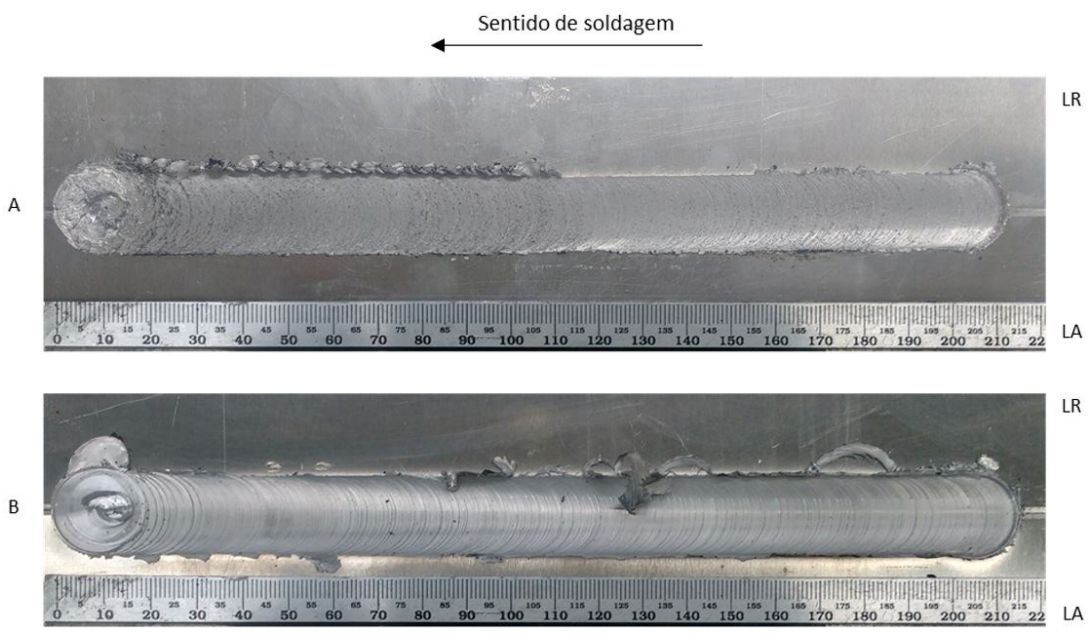

Figura 12. Soldas de topo realizadas nas chapas de alumínio 5052 H34 com a ferramenta usada (A) e com a ferramenta nova (B).

\subsection{Caracterização das juntas soldadas}

\subsubsection{Ensaio de tração}

Com o objetivo de verificar a eficiência da junta soldada obtida pelo processo FSW, corpos de prova foram submetidos a ensaios de tração, confeccionados e ensaiados conforme as normas e procedimentos descritos na seção 3.2.4 deste documento. A Tabela 5 faz referência aos resultados obtidos com as amostras retiradas do metal de base da liga de alumínio 5052 H34 e a Tabela 6 diz respeito aos testes realizados com os três corpos de prova retirados do início, do meio e do fim do cordão de solda. Pela análise da Tabela 5, verifica-se que os valores encontrados para o metal de base estão de acordo com os valores mínimos estabelecidos pela norma ASTM B209M [9].

Tabela 5. Propriedades mecânicas do metal de base da liga Al 5052 H34.

\begin{tabular}{|c|c|c|c|c|c|c|}
\hline $\begin{array}{l}\text { Propriedades } \\
\text { Mecânicas }\end{array}$ & MB1 & MB2 & MB3 & Média & $\begin{array}{l}\text { Desvio } \\
\text { Padrão }\end{array}$ & $\begin{array}{l}\text { Valores Mínimos } \\
\text { Especificados }\end{array}$ \\
\hline бesc [MPa] & 187,47 & 193,12 & 201,96 & 194,18 & 7,30 & 180 \\
\hline omáx [MPa] & 240,78 & 244,86 & 253,26 & 246,30 & 6,36 & 235 \\
\hline$\varepsilon[\%]$ & 6,80 & 6,31 & 6,65 & 6,59 & 0,25 & 6 \\
\hline
\end{tabular}

Tabela 6. Propriedades mecânicas da junta soldada por FSW da liga Al 5052 H34.

\begin{tabular}{ccccccc}
\hline $\begin{array}{c}\text { Propriedades } \\
\text { Mecânicas }\end{array}$ & TR1 & TR2 & TR3 & Média & Desvio Padrão & Eficiência [\%] \\
\hline бesc [MPa] & 90,04 & 86,97 & 105 & 93,99 & 9,63 & 48,40 \\
omáx $[\mathrm{MPa}]$ & 185,4 & 167,8 & 206,3 & 186,49 & 19,25 & 75,72 \\
$\varepsilon[\%]$ & 10,53 & 8,98 & 15,47 & 11,66 & 3,389 & 100,00 \\
\hline
\end{tabular}

A eficiência da junta soldada verificada na Tabela 6 foi calculada tomando como base os valores médios do limite de escoamento, do limite de resistência e do alongamento, obtidos na caracterização do metal de base. Foi verificada uma eficiência de cerca de $76 \%$ para a tensão máxima das juntas soldadas quando comparada ao material de base. Fioravanti [14] fez uma lista com diversos resultados de eficiência de juntas soldadas por FSW para diferentes ligas de alumínio, em que os valores variaram de $43 \%$ a $95 \%$, sendo a média de $70 \%$. Capelari e Mazzaferro [4] obtiveram uma eficiência de 90,4\% em soldas realizadas na liga de alumínio 5052 H34 com 6,35 mm de espessura, soldadas com uma ferramenta com pino cônico liso. 
Verifica-se na Figura 13 as amostras (TR1, TR2 e TR3) após os ensaios de tração, em que as linhas traço e ponto indicam a interface de soldagem e as setas evidenciam o local onde houve a ruptura do corpo de prova. Verifica-se que a amostra TR1 rompeu exatamente na linha de soldagem, enquanto as amostras TR2 e TR3 romperam no lado de avanço e retrocesso, respectivamente, adjacentes à linha de soldagem. As amostras TR2 e TR3 romperam a $3 \mathrm{~mm}$ e $3,5 \mathrm{~mm}$ da interface de soldagem, respectivamente.
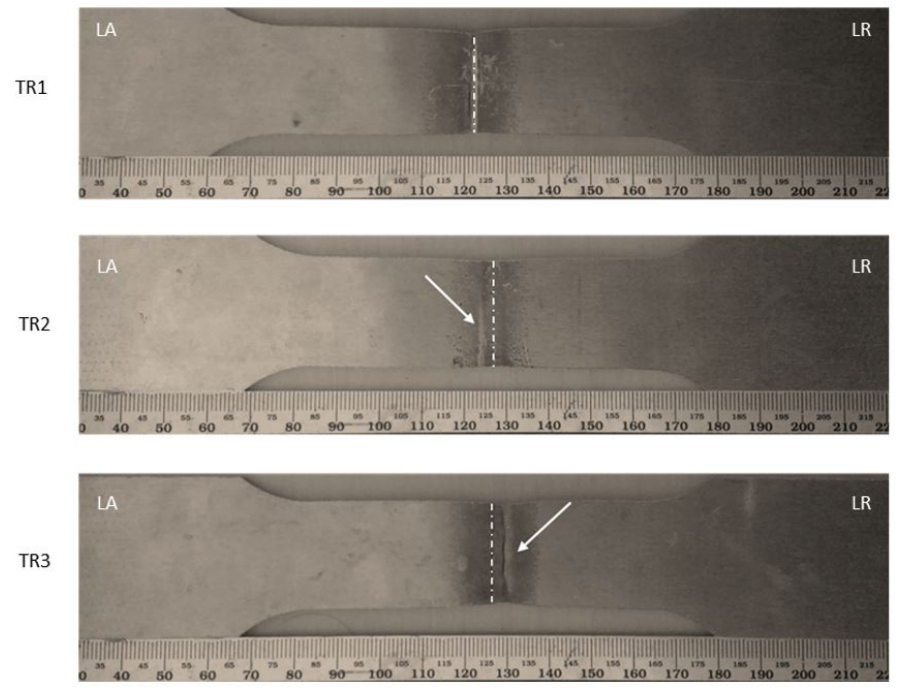

Figura 13. Corpos de prova após o ensaio de tração.

O alto desvio padrão encontrado para os valores de tensão de ruptura das amostras, combinado com as variações de posição das fraturas dos corpos de prova após os ensaios de tração, indicam a existência de uma heterogeneidade nos corpos de prova ensaiados. A heterogeneidade do processo pode ter sido originada a partir de uma possível variação da penetração do pino ao longo do processo de soldagem. Esse fato pode ser explicado pela maior formação de rebarbas no cordão de solda, a partir do centro, conforme observado na Figura 12A. Além disso, as marcas apresentadas na raiz da solda, observadas na Figura 13, indicam que foram obtidos maiores valores de temperatura no início e no fim do processo de soldagem, proporcionando melhores resultados no ensaio de tração para as amostras TR1 e TR3. Dessa forma, a maior penetração da ferramenta durante o processo pode ter contribuído para o aumento da temperatura e para a formação de uma união mais efetiva, bem como ausente de defeitos na raiz da solda que comprometessem os ensaios de tração.

\subsubsection{Análise metalográfica}

A macrografia da junta soldada é apresentada na Figura 14, em que a linha tracejada representa a interface de soldagem, ou seja, o local onde o pino da ferramenta foi inserido. Verifica-se as rebarbas no lado do avanço da ferramenta e a região em destaque na amostra indica o intenso trabalho mecânico ao qual o material foi submetido.

Foi identificado o baixo comprimento das rebarbas, localizadas apenas no lado de avanço e foi verificada a ausência do defeito conhecido como "kissing bond", que é decorrente da falta de penetração do pino na raiz e insuficiência do fluxo de material [24]. Não houve a redução significativa da espessura das chapas na região da soldagem e não foram identificados problemas comuns no processo como porosidade e vazios dispersos ou contínuos no interior ou na superfície da solda. Sabe-se que tais defeitos proporcionam mau acabamento superficial e queda nas propriedades mecânicas da junta. Dessa forma, foi possível obter com os parâmetros usados soldas com bom aspecto superficial, ausência de rebarbas e defeitos internos e junta com penetração total. Além disso, é possível afirmar que o desempenho da ferramenta com pino cônico liso se mostrou eficiente na execução da solda, já que não foi possível notar a presença de vazios e a formação da seção transversal da junta soldada tem aspecto regular em toda a extensão da junta soldada. 
Validação de um Sistema Robotizado Recém Desenvolvido para a Soldagem pelo Processo Friction Stir Welding por meio da União e Caracterização de Juntas da Liga de Alumínio 5052 H34

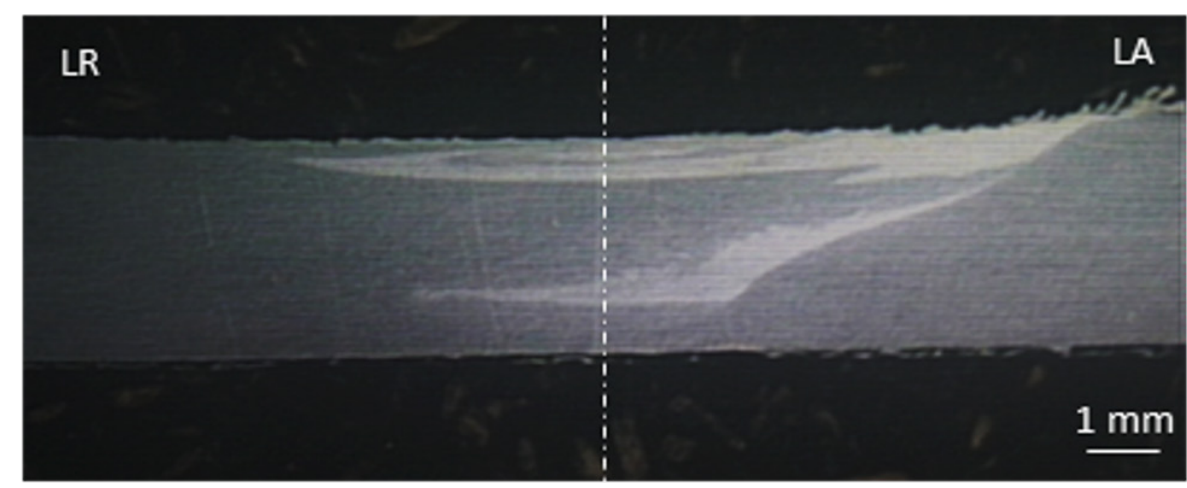

Figura 14. Macrografia da liga alumínio 5052 H34 soldada pelo processo FSW.

Entretanto, o ataque químico realizado com o reagente ácido fluorídrico $1 \%$ não proporcionou uma revelação satisfatória das zonas formadas na solda. $O$ ataque químico não permitiu identificar com clareza a extensão da zona misturada e não revelou a formação de uma zona afetada pelo calor na solda. A formação de anéis concêntricos, conhecidos na literatura como "onion rings", também não foi visualizada na região da mistura. O mesmo ocorreu com Gipiela [22] ao utilizar o reagente Keller modificado para a análise da mesma liga de alumínio usada neste projeto.

Os anéis concêntricos podem se formar e desaparecer parcialmente ou completamente sob certas condições, como composição química do material, recristalização do material durante o processo e espessura da chapa. Chen et al. [25] e Marzoli et al. [26] descobriram que a formação dos "onion rings" não era visível no lado de avanço, mas claramente visível no lado de retrocesso durante a soldagem de ligas de alumínio. Tal fato foi atribuído à recristalização parcial que ocorreu no lado de avanço e impedia o fluxo do material. Ni et al. [27] e Wang et al. [28] relataram que não haviam anéis concêntricos em soldas realizadas em ligas de alumínio e consideraram a redução da espessura como fator responsável pelo desaparecimento do fenômeno.

De acordo com Kumar et al. [29] é necessário um gradiente térmico entre os lados de avanço e retrocesso para a formação dos anéis concêntricos. Segundo o autor, quando o material plastificado atinge a região mais fria (lado de retrocesso), o mesmo tem sua movimentação restringida pelo ombro da ferramenta, que o impõe a realizar o percurso de rotação completo até atingir o lado de avanço. Dessa forma, é possível que neste projeto o baixo valor da velocidade de avanço não tenha permitido, juntamente com o baixo valor da espessura das chapas, a formação de uma diferença significativa de temperatura entre os lados de avanço e retrocesso que favorecessem a formação dos anéis.

\subsubsection{Ensaio de dureza por microindentação}

Foram realizadas medições de microdureza à meia espessura das amostras soldadas, conforme apresentado na metodologia. Verifica-se pela análise da Figura 15 os valores de dureza ao longo da junta, considerando o ponto zero como o centro da solda. Verifica-se também os lados de avanço (LA) e retrocesso (LR), bem como a curva de tendência do perfil de dureza.

Segundo Kozminski [23] alguns fatores podem influenciar a dureza da junta soldada, tais como a composição química e o grau de encruamento do material de base, os efeitos metalúrgicos intrínsecos do processo de FSW bem como os parâmetros empregados. Com isso, a comparação entre os valores de dureza da região soldada e do material de base são importantes, pois podem indicar uma perda de ductilidade, eventualmente comprometendo a junta soldada. Além disso, servem como apoio para a análise dos testes mecânicos destrutivos.

De acordo com Kim et al. [30], geralmente, na região da mistura da solda há um aumento de dureza e resistência, em função do trabalho mecânico a quente e consequente refinamento na estrutura granular, dispersão de compostos intermetálicos, quebra da estrutura dendrítica original e a reduzida probabilidade de formação de defeitos volumétricos do tipo vazio. Verificou-se pela análise da Figura 15, entretanto, uma queda da dureza na região soldada, quando comparada ao metal de base, que está de acordo com os trabalhos de Gipiela e Martins [22], que soldaram material similar e com a mesma espessura. A hipótese criada pelos autores para a ocorrência da 


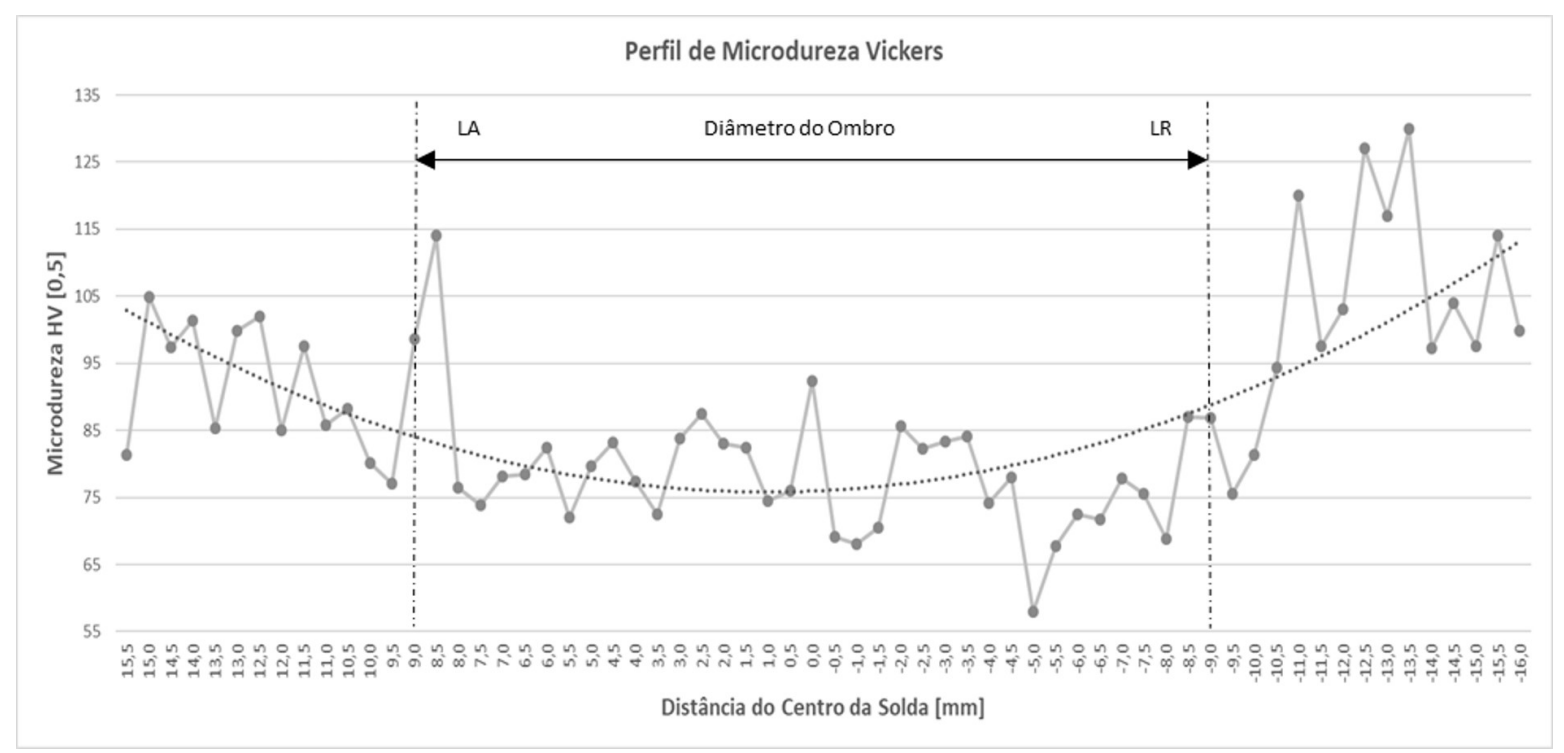

Figura 15. Perfil de microdureza Vickers da solda por FSW da liga de alumínio 5052 H34.

queda da microdureza na zona misturada é de que uma baixa densidade de discordâncias foi gerada a partir da recuperação dinâmica e recristalização dos grãos da região em que foi observada a queda. Além disso, o fenômeno de queda da microdureza na região da mistura pode ser explicado pelo tempo de exposição do material às temperaturas envolvidas no processo, uma vez que foi utilizado baixo valor de velocidade de avanço. Dessa forma, o aquecimento do material foi homogêneo, assim como o resfriamento mais lento, o que explica a eficiência na mistura do material e ausência de defeitos internos.

\subsubsection{Medidas de temperatura}

Os pontos de medição de temperatura no sistema de soldagem, bem como os valores máximos obtidos durante todo o processo são apresentados na Figura 16. Verifica-se que a temperatura máxima obtida na carcaça do sistema foi de $58^{\circ} \mathrm{C}$. De acordo com o catálogo do redutor, o mesmo pode ter temperatura de trabalho externa de até $70{ }^{\circ} \mathrm{C}$, uma vez que a temperatura interna do sistema é de aproximadamente $15{ }^{\circ} \mathrm{C}$ acima da externa. Temperaturas acima dessa faixa reduzem a viscosidade do óleo causando desgastes no redutor, exigindo trocas mais frequentes.

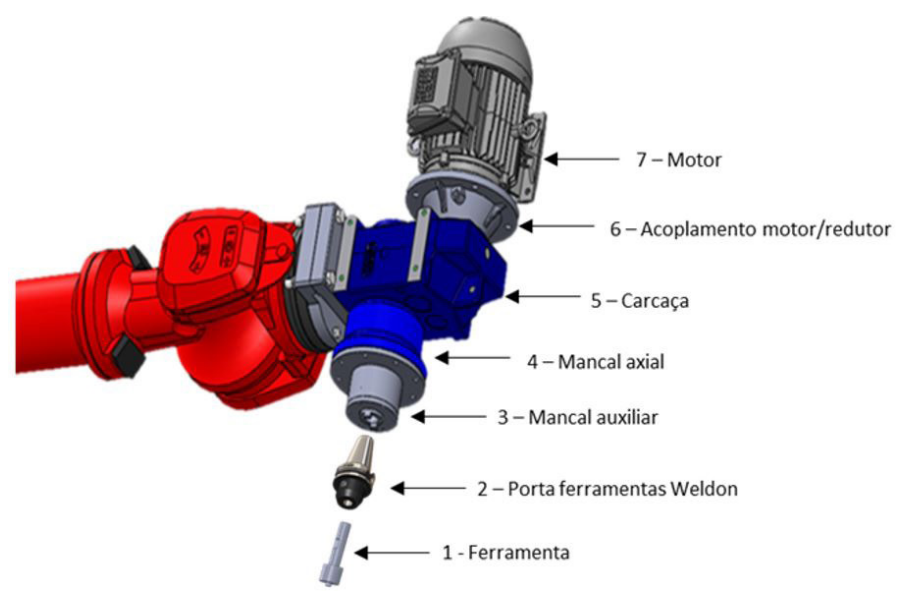

\begin{tabular}{cc}
\hline Ponto de Medição & $\begin{array}{c}\text { Temperatura } \\
\text { Máxima }\left[\mathrm{C}^{\circ}\right]\end{array}$ \\
\hline 7 & 39 \\
\hline 6 & 49 \\
\hline 5 & 51 \\
\hline 4 & 58 \\
\hline 3 & 72 \\
\hline 2 & 210 \\
\hline 1 & $*$ \\
\hline
\end{tabular}

Figura 16. Pontos de verificação da temperatura no sistema de soldagem e temperaturas máximas atingidas. 
Validação de um Sistema Robotizado Recém Desenvolvido para a Soldagem pelo Processo Friction Stir Welding por meio da União e Caracterização de Juntas da Liga de Alumínio 5052 H34

O mancal auxiliar, por sua vez, não possui lubrificação interna e atingiu a temperatura máxima de $72{ }^{\circ} \mathrm{C}$ durante o processo. Entretanto, os rolamentos $3210 \mathrm{~B}$ e $6210 \mathrm{ZZ}$ dimensionados para funcionar na parte interna do mancal auxiliar podem trabalhar em faixas de temperatura de até $120^{\circ} \mathrm{C}$ [31].

O porta ferramentas atingiu a temperatura máxima de $210{ }^{\circ} \mathrm{C}$ durante o processo e as medidas tomadas no ombro da ferramenta indicaram o valor máximo de $160^{\circ} \mathrm{C}$. O valor errôneo de temperatura apresentado no ombro da ferramenta deve-se à emissividade do material AISI H13 e à emissividade fixa do aparelho usado nas medições que é de 0,95. Dessa forma, o valor de temperatura apresentado para o ombro deve ser desprezado, já que dados coletados experimentalmente por outros autores indicam temperaturas acima de $300^{\circ} \mathrm{C}$ para a região do ombro da ferramenta [32].

Conforme detalhado na metodologia, foram realizados dois testes para a verificação da temperatura nas chapas de alumínio, em que quatro termopares foram dispostos no centro da amostra, perpendiculares à linha de soldagem. Os resultados dos picos de temperatura são apresentados na Figura 17, em que são diferenciados os lados de avanço (positivo) e retrocesso (negativo). O ponto zero indica a interface de soldagem, e as linhas tracejadas correspondem ao diâmetro do ombro da ferramenta.
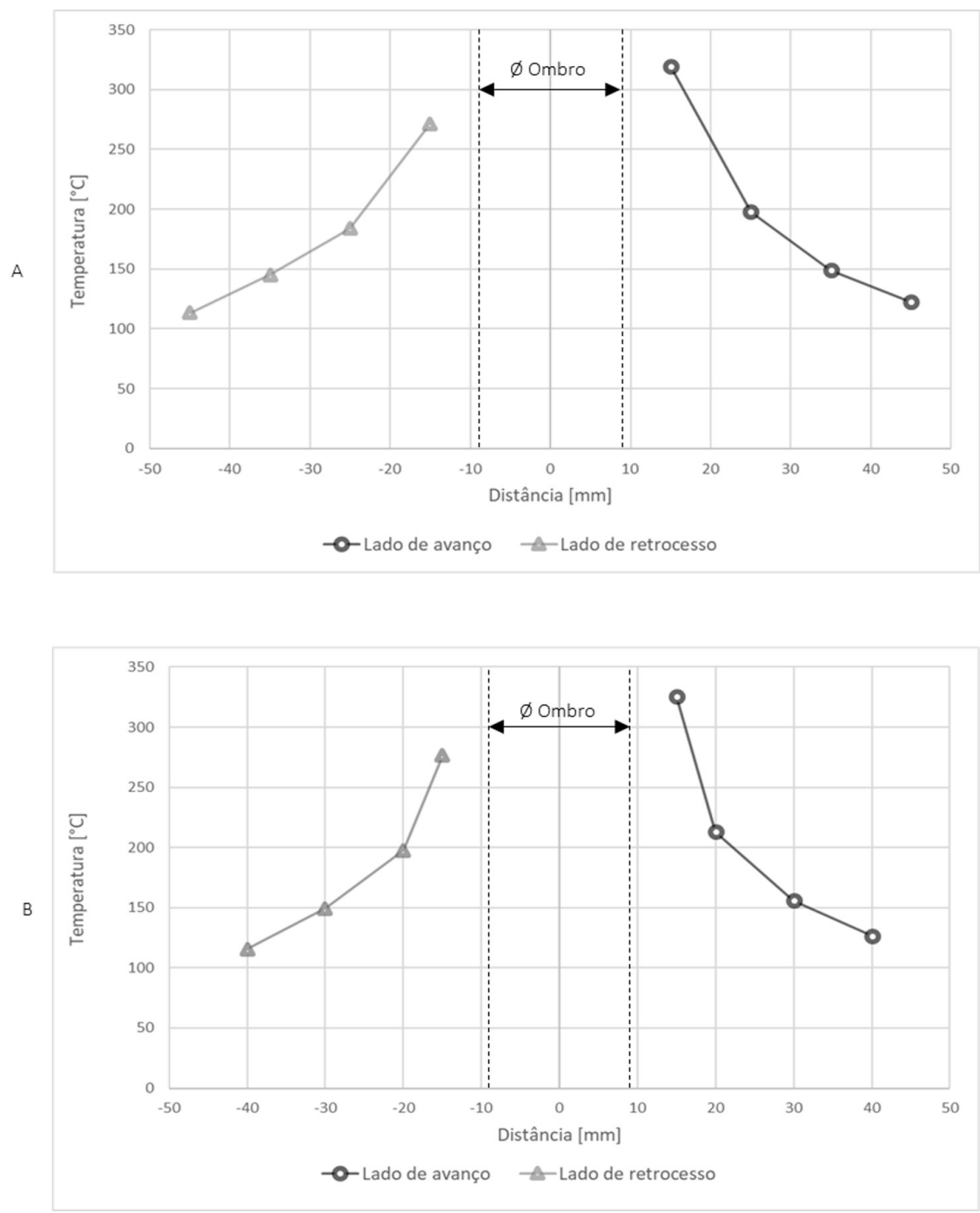

Figura 17. Picos de temperatura durante a soldagem da liga $5052 \mathrm{H} 34$. (A) termopares (T1, T2, T3 e T4) posicionados a 15, 25, 35 e $45 \mathrm{~mm}$ da interface de soldagem; (B): termopares (T1, T2, T3 e T4) posicionados a 15, 20, 30 e $40 \mathrm{~mm}$ da interface de soldagem. 
A Figura 17A é referente ao teste realizado com os termopares (T1, T2, T3 e T4) posicionados a 15, 25, 35 e $45 \mathrm{~mm}$ da interface de soldagem, e a Figura 17B, é referente ao teste realizado com os termopares (T1, T2, T3 e T4) posicionados a 15, 20, 30 e $40 \mathrm{~mm}$ da interface de soldagem. Verifica-se um comportamento semelhante nos dois testes, sendo o pico de temperatura na faixa de $315^{\circ} \mathrm{C}$ no termopar T1, no tempo em que a ferramenta atinge $o$ centro da chapa no lado de avanço.

Verificou-se que em ambos os casos o lado de avanço apresentou temperaturas de pico aproximadamente $15 \%$ maiores que o lado de retrocesso. De acordo com Mishra e Ma [33], o material plastificado é rotacionado a partir do lado de avanço e, simultaneamente, sobrepõe-se ao pino em direção ao lado de retrocesso. Dessa forma, a região de avanço é submetida a maiores esforços, formando regiões com diferentes níveis de refinamento, tamanho grão e fração volumétrica das partes presentes. Esses fenômenos fazem com que as temperaturas sejam maiores no lado do avanço. De acordo com James et al. [34], no lado do avanço a velocidade de translação ao longo da linha de junção soma-se à velocidade de rotação da ferramenta e no lado do retrocesso a velocidade de rotação é subtraída da velocidade de translação. Firouzdor [35] afirma que o maior aquecimento ocorre no lado de avanço, o que o faz posicionar materiais com maior resistência mecânica neste lado durante a soldagem de materiais dissimilares.

Os valores encontrados nos ensaios estão equivalentes aos resultados encontrados por diversos pesquisadores que verificaram tanto virtualmente quanto experimentalmente a distribuição de temperatura durante o processo [36-38]. Nunes [39] fez um importante levantamento para a NASA (National Aeronautics and Space Administration), em que foram identificadas experimentalmente as temperaturas durante a soldagem de chapas de alumínio, variando-se diversos parâmetros. $\mathrm{O}$ autor encontrou picos de temperatura na faixa de $450^{\circ} \mathrm{C}$ na linha de soldagem e temperaturas na faixa de $300^{\circ} \mathrm{C}$ a $16 \mathrm{~mm}$ da linha de soldagem. A amostra soldada com os

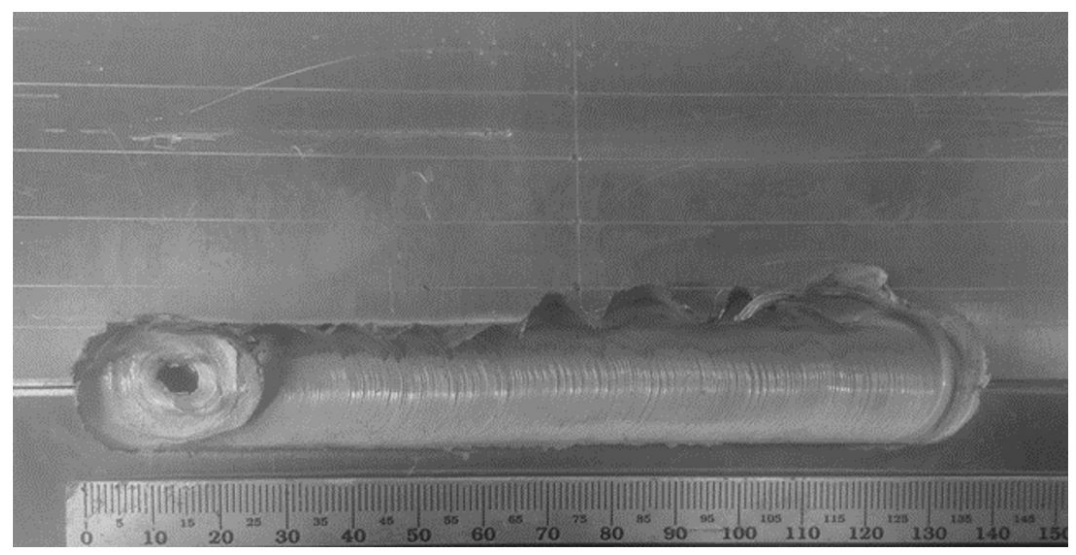

Figura 18. Amostra soldada com os termopares (T1, T2, T3 e T4) posicionados no lado do retrocesso a 15, 25, 35 e $45 \mathrm{~mm}$ da interface de soldagem.

termopares (T1, T2, T3 e T4) posicionados no lado do retrocesso a 15, 25, 35 e $45 \mathrm{~mm}$ da interface de soldagem é apresentada na Figura 18.

\section{Conclusões}

A partir dos resultados e discussões apresentadas neste trabalho, serão apresentadas a seguir as principais conclusões:

1.O sistema de soldagem projetado se mostrou eficaz em aplicações de soldagem FSW, apresentando torque e resistência mecânica suficientes para a união de materiais com baixo ponto de fusão; 
Validação de um Sistema Robotizado Recém Desenvolvido para a Soldagem pelo Processo Friction Stir Welding por meio da União e Caracterização de Juntas da Liga de Alumínio 5052 H34

2. O sistema de soldagem projetado atingiu temperaturas de trabalho compatíveis com os elementos mecânicos dimensionados (Spindle, rolamentos, porta ferramentas, mancal auxiliar, dentre outros), tendo sua lubrificação atuada de forma eficiente;

3. Não foram identificados ruídos, vibrações ou esforços anormais advindos do sistema de soldagem projetado. Para a redução das vibrações advindas dos braços do robô pode-se utilizar estratégias como: preferencialmente utilizar robôs paralelos ou cartesianos; ao utilizar robôs antropomórficos, posicionar a mesa de soldagem o mais próximo possível da base do robô; fazer uso de guias de soldagem ao utilizar robôs antropomórficos;

4.0 sistema de soldagem projetado poderá ser usado também na soldagem de materiais com elevado ponto de fusão, sendo necessários testes físicos para a determinação dos parâmetros ideais para cada situação particular;

5. Por meio dos parâmetros utilizados, bem como da geometria da ferramenta escolhida (pino cônico liso), foi possível obter juntas da liga de alumínio 5052 H34 soldadas com: bom aspecto superficial, baixos valores de rebarba, ausência de sulcos ou vazios ao longo da linha de soldagem e com penetração total.

\section{Agradecimentos}

Ao LRSS (Laboratório de Robótica Soldagem e Simulação) da UFMG e à CAPES (Coordenação de Aperfeiçoamento de Pessoal de Nível Superior), pelo apoio e investimento à pesquisa. À COMAU do Brasil pela parceria e empréstimo do robô SMART NJ500, indispensável à essa pesquisa. A empresa Geremia Redutores, pelo apoio à pesquisa por meio da doação do redutor GD49, destinado à adaptação ao sistema de soldagem. Ao CEFET-MG, por ter cedido as máquinas para a fabricação das ferramentas de soldagem e disponibilizado os laboratórios para a execução dos ensaios destrutivos.

\section{Referências}

[1] Thomas WM, Nicholas ED, Needham JC, Murch MG, Temple-Smith $P$, Dawes CJ. Improvements relating to friction welding. International Patent Application PCT/GB92/02203 and GB Patent Application 9125978.8. London, UK Patent Office. 1991 Dec 6 [acesso em 20 set. 2017]. Disponível em: https:// www.google.ch/patents/CA2123097C?cl=en.

[2] Fonseca EB. Simulação física do processo de soldagem por atrito com pino não consumível do aço inoxidável duplex UNS S32205 [tese de doutorado] Campinas: Unicamp; 2013.

[3] Ferlin AS. Monitoramento do processo de junção por Friction Stir Welding para detecção de falhas. [tese de doutorado] Campinas: Unicamp; 2013.

[4] Capelari TV. Avaliação da geometria de ferramenta e parâmetros do processo FSW na soldagem da liga de alumínio AA 5052 [dissertação de mestrado]. Porto Alegre: Universidade Federal do Rio Grande do Sul; 2006.

[5] Backer J. Feedback control of robotic friction stir welding [Phd thesis]. Sweden: University West; 2014.

[6] Almeida DT. Análise microestrutural e avaliação mecânica de juntas soldadas por fricção e mistura mecânica (FSW) da liga de alumínio 5182-0 [dissertação de mestrado]. Porto Alegre: Universidade Federal do Rio Grande do Sul; 2015.

[7] Gibson BT. The development of in-process monitoring and control techniques for aerospace applications of Friction Stir Welding [doctor thesis]. Nashville: Vanderbilt University, 2015.

[8] Associação Brasileira de Normas Técnicas. ABNT NBR 6835: alumínio e suas ligas - classificação das têmperas. São Paulo: ABNT; 2006.
[9] American Society for Testing and Materials. ASTM B209M: standard specification for aluminum and aluminum-alloy sheet and plate. West Conshohocken: ASTM; 2001. 29 p.

[10] Colligan K. Material flow behavior during friction welding of aluminum. Welding Journal. 1999;75(7):229s-237s.

[11] Guerra M, Schmidt C, McClure JC, Murr LE, Nunes AC. Flow patterns during friction stir welding. Materials Characterization. 2002;49(2):95101. http://dx.doi.org/10.1016/S1044-5803(02)00362-5.

[12] Thomas WM. Friction stir welding tool and method. UK Publication Number GB 2306366. United Kingdon: Crown Copyright; 1996 Out [acesso em 20 set. 2017]. Disponível em: http://www.patent.gov.uk.

[13] Zhao Y, Lin S, Wu L, Qu F. The influence of pin geometry on bonding and mechanical properties in friction stir weld 2014 Al alloy. Journal Materials Letters. 2005;59(23):2948-2952. http://dx.doi.org/10.1016/j.matlet.2005.04.048.

[14] Fioravanti AS. Soldagem por FSW de ligas de alumínio Alcalad AA2024-T3 e AA7075-T6 [dissertação de mestrado]. Porto Alegre: Universidade Federal do Rio Grande do Sul; 2008.

[15] Zhang YN, Cao X, Larose S, Wanjara P. Review of tools for friction stir welding and processing. Canadian Metallurgical Quarterly. 2012;51(3):250-261. http://dx.doi.org/10.1179/18 79139512 Y.0000000015.

[16] International Standard Organization. ISO 25239-4: friction stir welding - aluminium - specification and qualification of welding procedures. Genebra, Suíça: ISO; 2011.

[17] International Standard Organization. DIN EN ISO 4136: destructive tests on welds in metallic materials - transverse tensile test. Genebra, Suíça: ISO; 2013. 
[18] Associação Brasileira de Normas Técnicas. ABNT NBR 7549: alumínio e suas ligas - produtos laminados, extrudados e fundidos - ensaio de tração. São Paulo: ABNT; 2011.

[19] Zhu XK, Chao YJ. Numerical simulation of transient temperature and residual stresses in friction stir welding of 304L stainless steel. Journal of Materials Processing Technology. 2004;146(2):263272. http://dx.doi.org/10.1016/j.jmatprotec.2003.10.025.

[20] Smith CB. Robotic friction stir welding using a standard industrial robot. Journal of Light Metal Welding and Construction. 2004;42(3):40-41.

[21] Thomas WM, Threadgill PL, Nicholas ED. Feasibility of friction stir welding steel. Science and Technology of Welding and Joining. 1999;4(6):365-372. http://dx.doi.org/10.1179/13621 7199101538012 .

[22] Gipiela ML, Martins F. Influência dos parâmetros de processo na soldagem da liga de alumínio 5052 pelo processo FSW. In: Associação Brasileira de Engenharia e Ciências Mecânicas. Anais do 80 COBEF - Congresso Brasileiro de Engenharia de Fabricação; 2015 maio 18-22; Salvador, Bahia. Rio de Janeiro: ABCM; 2015. 7 p.

[23] Kozminski ELO. Análise microestrutural e avaliação mecânica de juntas soldadas por fricção e mistura mecânica (FSW) do aço inoxidável duplex UNS S31803 [dissertação de mestrado]. Porto Alegre: Universidade Federal do Rio Grande do Sul; 2015.

[24] Carvalho DACV. Comportamento mecânico de juntas T soldadas por fricção linear na liga AA6082 [dissertação de mestrado]. Coimbra: Faculdade de Ciências e Tecnologia da Universidade de Coimbra; 2015.

[25] Chen X-G, da Silva M, Gougeon P, St-Georges L. Microstructure and mechanical properties of friction stir welded AA6063-B 4 C metal matrix composites. Materials Science and Engineering A. 2009;518(1):174-184. http://dx.doi.org/10.1016/j.msea.2009.04.052.

[26] Marzoli LM, Strombeck A, Dos Santos JF, Gambaro C, Volpone LM. Friction stir welding of an AA6061/AI $203 / 20$ p reinforced alloy. Composites Science and Technology. 2006;66(2):363-371. http://dx.doi.org/10.1016/j.compscitech.2005.04.048.

[27] Ni DR, Chen DL, Wang D, Xiao BL, Ma ZY. Influence of microstructural evolution on tensile properties of friction stir welded joint of rolled SiCp/AA2009-T351 sheet. Materials \& Design. 2013;51:199205. http://dx.doi.org/10.1016/j.matdes.2013.04.027.

[28] Wang $D$, Xiao BL, Wang QZ, Ma ZY. Evolution of the microstructure and strength in the nugget zone of friction stir welded $\mathrm{SiCp} /$ $\mathrm{Al}-\mathrm{Cu}-\mathrm{Mg}$ composite. Journal of Materials Science and
Technology. 2014;30(1):54-60. http://dx.doi.org/10.1016/j. jmst.2013.09.018.

[29] Kumar KSVK, Kailas SV. KAILAS, Satish V. The role of friction stir welding tool on material flow and weld formation. Materials Science and Engineering A. 2008;485(1):367-374. http://dx.doi. org/10.1016/j.msea.2007.08.013.

[30] Kim YG, Fujii H, Tsumura T, Komazaki T, Nakata K. Three defect types in friction stir welding of aluminum die casting alloy. Materials Science and Engineering A. 2006;415(1):250-254 http://dx.doi.org/10.1016/j.msea.2005.09.072.

[31] NSK. Motion \& control: catálogo geral. 2017 [acesso em 20 set. 2017]. Disponível em: http://www.nsk.com.br.

[32] López EAT. Simulación computacional de la transferencia de calor en herramientas usadas en soldadura por fricción-agitación. Revista UIS Ingenierías. 2016;14(2).

[33] Mishra R, Mahoney M, Sato Y, Hovanski Y, Verma R. Friction Stir Welding and Processing VII. Cham: Springer International Publishing; 2005. 362 p. The Minerals, Metals \& Materials Series. https://doi.org/10.1007/978-3-319-48108-1.

[34] James MN, Bradley GR, Lombard H, Hattingh DG. The relationship between process mechanisms and crack paths in friction stir welded 5083-H321 and 5383-H321 aluminium alloys. Fatigue \& Fracture of Engineering Materials \& Structures. 2005;28(1-2):245 256. http://dx.doi.org/10.1111/j.1460-2695.2004.00830.x.

[35] Firouzdor V, Kou S. Al-to-Mg friction stir welding: effect of positions of $\mathrm{Al}$ and $\mathrm{Mg}$ with respect to the welding tool. Welding Journal. 2009;88(11):213-224.

[36] Bhatt KD, Pillai B. Simulation of Peak Temperature \& Flow Stresses during Friction Stir Welding of AA7050-T7451 Aluminum Alloy Using Hyper works. International Journal of Emerging Technology and Advanced Engineering. 2012;2250:2459.

[37] Keivani R, Bagheri B, Sharifi F, Ketabchi M, Abbasi M. Effects of pin angle and preheating on temperature distribution during friction stir welding operation. Transactions of Nonferrous Metals Society of China. 2013;23(9):2708-2713. http://dx.doi. org/10.1016/S1003-6326(13)62788-0.

[38] Santiago D; Urquiza S; Lombera G; Vedia L. 3D modeling of material flow and temperature in Friction Stir Welding. Soldagem \& Inspeção. 2009;14(3):248-256.

[39] Tang W, Guo X, McClure JC, Murr LE, Nunes A. Heat input and temperature distribution in Friction Stir Welding. Journal of Materials Processing \& Manufacturing Science. 1998;2(2):163172. http://dx.doi.org/10.1106/55TF-PF2G-JBH2-1Q2B. 